\title{
Platelet-concentrated and platelet poor-plasma promote different pattern on immunohistochemical expression of TGF- $\beta 1$, however they impairs the osteoneogensis in calvarial defects treated with autograft due suppression of osteocalcin
}

Marco Antonio de Oliveira-Filho ${ }^{1} \mathbb{D}$, Marcelo Souza ${ }^{2} \mathbb{B}$, Fernando Issamu Tabushi ${ }^{\mathbb{D}}$, Luís Eduardo Almeida ${ }^{4}$ (D) Fernanda Pirajá Figueiredo ${ }^{5}$ D, Elora Sampaio Lourenço ${ }^{6}$ (D), Allan Fernando Giovanini ${ }^{7, *}$, Osvaldo Malafaia ${ }^{8}$ (), Jurandir Marcondes Ribas Filho ${ }^{9}$ (D)

\footnotetext{
1. PhD. Medical Research Institute - Hospital Universitário Evangélico Mackenzie - Curitiba (PR), Brazil.

2. MsC. Medical Research Institute - Hospital Universitário Evangélico Mackenzie - Curitiba (PR), Brazil.

3. PhD. Medical Research Institute - Hospital Universitário Evangélico Mackenzie - Curitiba (PR), Brazil.

4. PhD. Assistant Professor. Marquette University - United States.

5. Graduate student. Hospital Universitário Evangélico Mackenzie - Curitiba (PR), Brazil.

6. Graduate student. Hospital Universitário Evangélico Mackenzie - Curitiba (PR), Brazil.

7. PhD. Medical Research Institute - Hospital Universitário Evangélico Mackenzie - Curitiba (PR), Brazil.

8. PhD. Medical Research Institute - Hospital Universitário Evangélico Mackenzie - Curitiba (PR), Brazil.

9. PhD. Medical Research Institute - Hospital Universitário Evangélico Mackenzie - Curitiba (PR), Brazil.
}

\begin{abstract}
Purpose: Herein we evaluated the effects of platelet concentrate (PC) and platelet-poor plasma (PPP) on bone repair using noncritical defects in the calvaria of rabbits and compared them to the presence of TGF- $\beta 1$ and osteocalcin on reparative sites. Methods: Five noncritical defects of $8.7 \mathrm{~mm}$ in diameter were created on the calvaria of 15 animals. Each defect was treated differently, using autograft $(A B G), A B G$ associated with PC (ABG + PC), ABG with PPP (ABG + PPP), isolated PPP, and blood clot (control). The animals were submitted to euthanasia on the second, fourth and sixth week post-surgery. Results: The defects that received ABG+PC or PPP demonstrated lower bone formation when compared to specimens that received $A B G$ in the same period. These results coincided to significant higher immunopositivity for TGF- $\beta 1$ for specimens that received PC, and lower presence of cytokine in the group PPP. However, either higher or lower presence of TGF- $\beta 1$ were also correlated to lower presence of osteocalcin. Likewise, these results were similar to findings in specimens treated only with PPP when compared to control. Conclusion: PC and PPP were not effective when applied in association with ABG. Similarly, isolated use of PPP was not beneficial in optimizing the bone repair.
\end{abstract}

Key words: Bone Regeneration. Osteocalcin. Transforming Growth Factor beta1. Rabbits.

*Corresponding author: afgiovanini@gmail.com | (55 41)3240-5488

Received: Feb 22, 2021 | Review: Apr 18, 2021 | Accepted: May 21, 2021

Conflict of interest: Nothing to declare.

Research performed at Medical Research Institute and Histopathology Laboratory, Hospital Universitário Evangélico Mackenzie, Curitiba (PR), Brazil. 
Platelet-concentrated and platelet poor-plasma promote different pattern on immunohistochemical expression of TGF- $\beta 1$, however they impairs the osteoneogensis in calvarial defects treated with autograft due suppression of osteocalcin

\section{Introduction}

It is an agreement in the literature that the use of autogenous particulate bone graft ( $A B G)$ has been considered the gold standard among graft materials for bone repair in craniofacial bone ${ }^{1}$. Because there are limited amounts of autograft available, researchers have suggested that the combination of autograft and nonimmunogenic biomaterials that may contribute to osteoconduction could be a likely alternative to produce adequate and faster bone repair ${ }^{1,2}$.

The platelet-rich plasma (PRP) constitutes the first generation of platelet concentrate (PC). This platelet concentrate is a blood product enriched with platelets and white cells in small amount of plasma obtained after immediate plasma centrifugation ${ }^{3}$. The premise about the use of PC on wound healing tissue is associated to the presence of platelets, that when activated release several amounts of growth factors that include PDGF, TGF-b, VEGF, IGF-1, and EGF ${ }^{4-6}$. Hypothetically, these growth factors, especially the TGF-b, may contribute to stem cells' mesenchymal chemotaxis, synthesis, and secretion of collagen on extracellular matrix, as well as to proliferation and cell differentiation into osteoblast, increasing the expression of osteocalcin, favoring bone tissue regeneration and osteoconduction 7,8. However, previous studies were not able to identify osteogenic action of PC when it was used alone to repair bone defects ${ }^{7,9}$.

The disagreement of a consistent result about the effect of PC on the osteogenesis has been discussed regarding the variations in the PRP production ${ }^{5}$. Herein, we produced and used a PC whose amount of platelets or leukocytes was not accessed. Thus, the centrifuged blood product used in this study may be only mentioned as PC, because it differs from Marx et al.' $\mathrm{s}^{3}$ protocol, that measured platelets at the same time that they removed leukocytes, or from Arnoczky et al.'s $\mathrm{s}^{10}$ protocol, that also accessed the number of platelets. Their protocols included white blood cells (leukocytes) in their final product. However, it should be highlighted that the PC protocol used here corroborates with several protocols previously published in literature and constitutes the majority of PC used in clinical and surgical practices ${ }^{5,9}$.

On the other hand, the platelet-poor plasma (PPP) corresponds to a level of plasma containing few platelets. Differently from PC, PPP contains an intense amount of serum proteins (e.g., fibrin, fibronectin, and vitronectin) that are important for cell adhesion $^{11}$. Actually, studies that have attempted to evaluate the effects of PPP in bone tissue are scarce and their results are uncertain. However, using an animal experimental study, Yilmaz et al. ${ }^{12}$ indicated PPP as a likely osteoinductive biomaterial, since they demonstrated the presence of PPP stimulates osteoblastic proliferation, increasing DNA synthesis and resulting in osteoblast proliferation.

Since neither PC nor PPP possess unanimous or robust results on craniofacial bone repair, herein we analyzed the osteoconduction effect stimulated by PC and PPP associated to autograft and PPP alone, in artificial bone defects created in rabbits calvaria. Yet, we compared the histological aspects of bone repair at two, four, and six weeks on immunohistochemical presence of TGF- $\beta 1$ and osteocalcin (OC) in order to understand the bone repair induced by $P C$ and PPP.

\section{Methods}

\section{Animal model}

This study was performed at the Institute of Medical Research of the Hospital Universitário Evangélico Mackenzie, after approval of its Ethics Committee.

Fifteen New Zealand female rabbits aged between 350 and 370 days old, weighing 2,850-4,400 g (3,244 g $\pm 388 \mathrm{~g})$, from the vivarium of the Institute of Medical Research, (IPEM) were used.

\section{Platelet concentrate and platelet-poor plasma preparation}

For the venous blood collection, the most favorable ear vein of each animal was punctioned using a scalp 21 . Afterwards, a $10-\mathrm{mL}$ syringe with $10 \%$ sodium citrate was connected to the scalp. Approximately $10 \mathrm{~mL}$ of blood from each rabbit was collected and transferred to a $160 \times 100-\mathrm{mm}$ tube. For the preparation of PC, a double-centrifugation technique was performed, as outlined in Fig. 1. At first, tubes containing blood material were centrifuged at $200 \mathrm{~g}$ for $20 \mathrm{~min}$, allowing the formation of two distinct fractions: plasma at the superior part of the tube (slightly yellow colored), and the blood cells at the bottom (red colored). All of the plasma fraction plus the upper part $(1 \mathrm{~mL})$ of the blood cells fraction were transferred to another tube and submitted to a second cycle of $400 \mathrm{~g}$ for $10 \mathrm{~min}$. After this last cycle, two distinct fractions could be identified. The upper fraction was removed to the point in which its reminiscent plus the bottom fraction completed a total of $1 \mathrm{~mL}$. After homogenization, $1 \mathrm{~mL}$ of final product from the initial $10 \mathrm{~mL}$ of blood 
was obtained and used as PC. The uppermost portion removed was used as PPP.

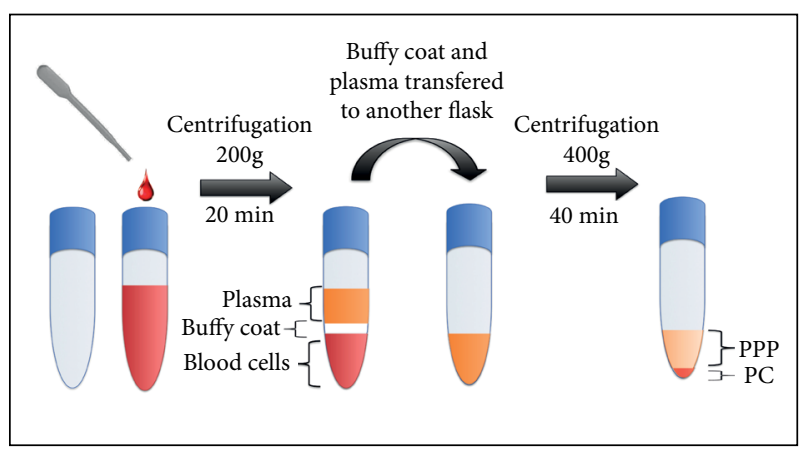

Figure 1 - Schematic model of platelet-poor plasma and platelet concentrate preparation.

\section{Sedation and surgical procedure}

The experimental surgical process was performed according to previous study published by Oliveira-Filho et al. ${ }^{9}$. Thus, for the surgical approach, the animals were positioned inside a campanula individually, and sedation was promoted with oxygen and isoflurane (Cristália, Itapira, SP, Brazil) followed by an intramuscular injection on the posterior part of the thigh with $2.3-\mathrm{g}$ xylazine $(0.52 \mathrm{mg} / \mathrm{kg})$ and 1.16 -g ketamine $(1.04 \mathrm{mg} / \mathrm{kg})$ (Vetbrands, Paulínia, SP, Brazil). Herein, the anesthesia protocol was sustained with isoflurane vaporization (Cristália, Itapira, SP, Brazil) using a facial mask. After the anesthesia induction, shaving and antisepsis prepared with $1 \%$ polyvinylpyrrolidone iodine (PVPI) solution of active iodine of the areas of calvaria were carried out.

A midline dermoperiosteal incision of $5 \mathrm{~cm}$ was performed, raising a periosteal skin flap to expose the parietal bones surface with total removal of the periosteum using a curette for bone. Five noncritical defects (considered $<10 \mathrm{~mm}$ in diameter in rabbits) measuring $8.7 \mathrm{~mm}$ in diameter $\square 2 \mathrm{~mm}$ in deep were created with a trephine drill (Biomedical Research Instruments, Silver Spring, MD, United States) under profuse saline solution irrigation.

Bone fragments that were removed from each calvarial defect were particulated and used as bone autografts. The fragmented bone obtained from the calvarial defects was created through an instrument for bone particulation developed by Neodent. A digital camera (Sony Cyber-shot DSC-w800, Tokyo, Japan) captured the images of the particles, whose average of particle size was obtained using ImageJ software (National Institutes of Health, Bethesda, MD, United States). An image size of $1 \mathrm{~mm}$ was used to standardize all measurements. Herein, the average particle size obtained was $882.52 \pm 36.38 \mathrm{~mm}^{2}$.

For PC and PPP coagulation, a mixture of $10 \%$ calcium chloride solution and 5,000 units of bovine thrombin was added to the previously prepared PC and PPP (1 min for gel formation). One defect was grafted with autogenous particulate bone graft (ABG), [anterior face, right side], another with $A B G$ associated with highly $P C(A B G+P C)$ [anterior face, left side], $A B G$ with PPP (ABG + PPP) [posterior face, right side], isolated PPP [posterior face, left side], and one defect had no grafting (control) [medial posterior face]. Tissue flaps of the wound were then closed in a running fashion.

For postoperative analgesia, the animals received morphine sulphate (3 mg/kg) (União Química, São Paulo, SP, Brazil) intramuscularly at the end of the surgery. Yet, the analgesia was maintained in postoperative period with 25 pills of paracetamol diluted into $500 \mathrm{~mL}$ of water placed into water drink for five days.

\section{Histological performance}

The animals were euthanatized with an overdose of the anesthetic solution after two weeks (five animals), four weeks (five animals), and six weeks (five animals). Block specimens were obtained using an inverted cone bur. The original surgical defect area and the surrounding tissues were removed in blocks. The pieces were fixed in $10 \%$ formalin for three days, and the surgical piece posteriorly was decalcified in $20 \%$ formic acid solution (Sigma-Aldrich, Darmstadt, Germany). Posteriorly, each piece was hemi-sectioned, perpendicularly to the sagittal suture. Longitudinal serial slices, measuring $5 \mathrm{~mm}$ of thickness, starting from the center of the original surgical defect, were obtained. The slices were stained with hematoxylin and eosin according the follow specification:

1. Deparaffinize sections, two changes of xylene, 15 minutes each;

2. Hydrate in two changes of absolute alcohol, 5 minutes each; 
3. $95 \%$ alcohol for 2 minutes following for $70 \%$ alcohol for 2 minutes;

4. Wash briefly in distilled water;

5. Stain in Harris hematoxylin solution for 5 minutes;

6. Wash in running tap water for 5 minutes;

7. Differentiate in $1 \%$ acid alcohol for 10 seconds;

8. Wash running tap water for 1 minute;

9. Wash in running tap water for 5 minutes;

10. Rinse in $95 \%$ alcohol, 10 dips;

11. Counterstain in eosin solution for 20 seconds;

12. Dehydrate using two changes on $75 \%$ alcohol, two changes of $95 \%$ alcohol and two changes of absolute alcohol, 5 minutes each;

13. Clear in two changes of xylene, 5 minutes each;

14. Mount with xylene based on Permount mounting medium (Sigma-Aldrich, Darmstadt, Germany).

\section{Immunohistochemical procedure}

Two- $\mu$ m thicknesses of each sample were deparaffinized in xylene and hydrated for 10 minutes in absolute alcohol, following $10 \mathrm{~min}$ each in $95 \%$ alcohol and $70 \%$ alcohol. The antigen retrieval process was performed using $1 \%$ pepsin solution ( $\mathrm{pH} 1.8$ ) (Sigma-Aldrich, Darmstadt, Germany) for 1 hour at $37^{\circ} \mathrm{C}$. They were allowed to cool to room temperature for $20 \mathrm{~min}$ and washed in distilled water for $10 \mathrm{~min}$. Endogenous peroxidase activity was blocked in $0.1 \%$ hydrogen peroxide (Thermo Fisher Scientific, Waltham, MA, United States) for $15 \mathrm{~min}$. The specimens were washed in running tap water for 5 minutes, and posteriorly submerged in phosphate-buffered saline (Sigma-Aldrich, Darmstadt, Germany) for 5 min.

Then, the samples were incubated overnight with the primary antibody anti-TGF- $\beta 1(200 \mathrm{mg} / \mathrm{mL})$ (Santa Cruz Biotechnology, Santa Cruz, CA, United States), dilution factor of 1:200, and anti-OC (200 mg/mL) (Santa Cruz Biotechnology, Santa Cruz, CA, United States), dilution factor of 1:150. To detect the primary antibodies, a labeled streptavidin biotin antibody-binding detection system was used (Universal HRP immunostaining kit) (Diagnostic BioSystems, Foster City, CA, United States), for $30 \mathrm{~min}$, and submitted to immersion with diaminobenzidine chromogen (Universal HRP immunostaining kit) (Diagnostic BioSystems, Foster City, CA, United States) for $15 \mathrm{~min}$. It produced a brownish precipitate at the antigen site. The specimens were counterstained with Harris's hematoxylin. A negative control was performed for all samples omitting primary antibody. For each specimen, three slides were utilized for incubation with each antibody.

\section{Histomorphometric and immunohistochemical analysis}

Image acquiring was done with the use of a light microscope (21/3, Quimis Aparelhos Científicos, Diadema, SP, Brazil) and an SDC-310 camera (Samsung, Seongnam, South Korea), according to a previously published methodology ${ }^{9}$. Three randomly selected microscopic fields within each grafted area from all groups and animals were analyzed.

Histomorphometric parameters were analyzed using the UTHSCSA Image Tool 2.00 (University of Texas Health Science Center, Houston, TX, United States). A total of $\approx 10 \mathrm{~mm}^{2}$ was analyzed in each field. Data were recorded in $\mathrm{mm}^{2}$ for each parameter. Simultaneously, the percentage of positive TGF- $\beta 1$ and OC were calculated by automation system, following the protocol established by Di Cataldo et al. ${ }^{13}$. This automated counting allowed counting only the percentage of protein present in the whole defect, but it was not possible to distinguish their immunopositivity for membrane, cytoplasm or extracellular matrix.

\section{Statistical analysis}

The bone matrix deposition was evaluated within the monitoring period. A Shapiro-Wilk analysis was used to determine the normality, followed by the Kruskal-Wallis nonparametric test, to verify significant differences among groups. A significance level of 0.05 was used for all analyses. Data were analyzed using the Statistical Package for the Social Sciences (SPSS Statistics) v. 20 computer program (IBM Corporation, Armonk, NY, United States).

\section{Results}

\section{Microscopic analysis}

The histological features for each group are demonstrated in Fig. 2. The quantitative data for the histomorphometric 
results for bone matrix presence in each group are given in Table 1. A concise description of the histological frame found in each group is provided ahead.

\section{Autogenous particulate bone graft}

In the second week post-surgery, new bone formation exhibiting basophilic reversal lines suggesting osteoconductor

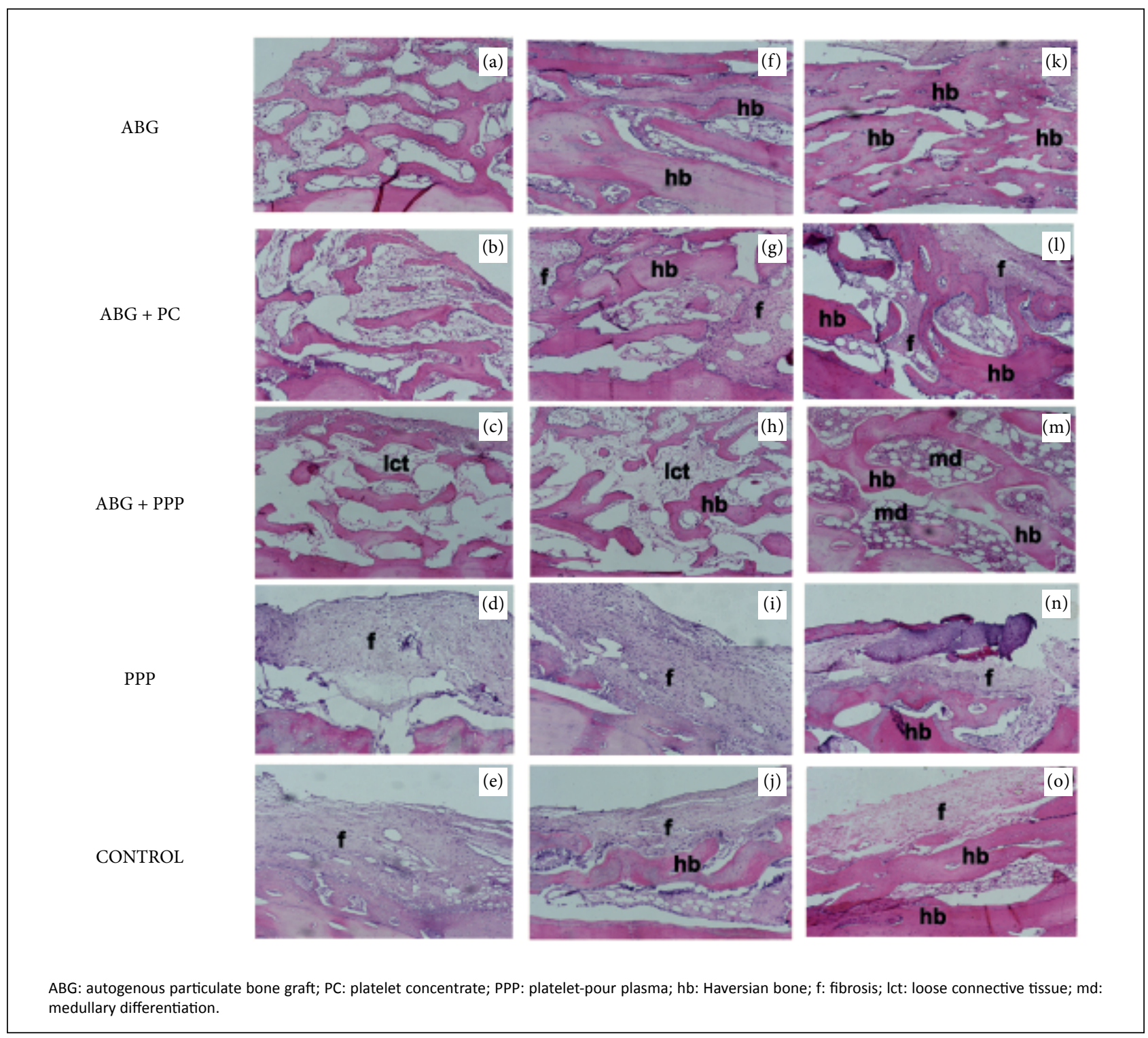

Figure 2 - Micrographs (a-e) demonstrate the histological characteristics in the $A B G, A B G+P C, A B G+P P P, P P P$ and control groups, respectively, two weeks after surgery. $A, B$ and $C$ reveal similar presence of autograph in the $A B G, A B G+P C$ and ABG + PPP groups, while connective tissue was predominant in the PPP (D) and control (E) groups. Micrographs (f-j) demonstrate the same groups four weeks after surgery. The larger bone deposition on the defect treated with only ABG is evident, while the osteoneogenesis was lower for the groups that received PC and PPP. The patterns of the PPP and control groups at four weeks were similar, but in the control group there was a scarce presence of bone matrix in the host bone. These patterns were similar to the sixth week (k-o). In this period, the intense presence of bone matrix in the ABG group may be seen. In the groups that received ABG + PC and ABG + PPP, the presence of osteogenesis was lower, while for the PPP and control groups the robust parts of the defects were composed of fibrotic tissue (hematoxylin and eosin stain, original magnification $\times 100)$. 
Table 1 - Histomorphometric analysis among the groups regarding bone matrix formation*,**.

\begin{tabular}{|c|c|c|c|c|c|c|c|}
\hline Time period & & & PPP & PPP+Autograft & PRP+Autograft & Autograft & Control \\
\hline \multirow{7}{*}{2 Weeks } & & & $2.91 \pm 0,75$ & $5.61 \pm 0,87$ & $6.08 \pm 1.03$ & $6.61 \pm 1.46$ & $2.84 \pm 0.29$ \\
\hline & PPP & $2.91 \pm 0.75$ & ---- & $<0.001$ & $<0.001$ & $<0.001$ & 0.916 \\
\hline & $A B G+P P P$ & $5.61 \pm 0.87$ & & ---- & $=0.461$ & $=0.123$ & $<0.001$ \\
\hline & $A B G+P C$ & $6.08 \pm 1.03$ & & & ---- & $=0.397$ & $<0.001$ \\
\hline & ABG & $6.61 \pm 1, .46$ & & & & ---- & $<0.001$ \\
\hline & Control & $2.84 \pm 029$ & & & & & ---- \\
\hline & & & $5.01+0.93$ & $6.08 \pm 1.69$ & $6.0 \pm 1.4$ & $8.24 \pm 1.18$ & $5.27 \pm 1.02$ \\
\hline \multirow[t]{6}{*}{4 Weeks } & PPP & $5.01 \pm 0.93$ & ---- & $=0.207$ & $=0.242$ & $<0.001$ & $=0.743$ \\
\hline & $A B G+P P P$ & $6.08 \pm 1.69$ & & ---- & $=0.922$ & $=0.018$ & $=0.341$ \\
\hline & $A B G+P C$ & $6.0 \pm 1.4$ & & & ---- & $=0.015$ & $=0.390$ \\
\hline & $A B G$ & $8.24 \pm 1.18$ & & & & ---- & $=0.002$ \\
\hline & Control & $5.27 \pm 1.02$ & & & & & ---- \\
\hline & & & $7.52 \pm 0.64$ & $7.73 \pm 1.41$ & $7.53 \pm 1.3$ & $9.64 \pm 1.43$ & $7.86 \pm 0.57$ \\
\hline \multirow[t]{5}{*}{6 Weeks } & PPP & $7.52 \pm 0.64$ & ---- & $=0.709$ & $=0.983$ & $=0.002$ & $=0.551$ \\
\hline & $A B G+P P P$ & $7.73 \pm 1.41$ & & ---- & $=0,725$ & $=0.004$ & $=0.821$ \\
\hline & $A B G+P C$ & $7.53 \pm 1.3$ & & & ---- & $=0.002$ & $=0.565$ \\
\hline & $A B G$ & $9.64 \pm 1.43$ & & & & ---- & $=0.006$ \\
\hline & Control & $7.86 \pm 0.57$ & & & & & ---- \\
\hline
\end{tabular}

*Non-parametric Kruskal-Wallis test was employed; ${ }^{* *} \mathrm{p}<0.05$ indicates statistical significance; PPP: platelet-pour plasma; ABG: autogenous particulate bone graft; PC: platelet concentrate; PRP: platelet-rich plasma.

activity was observed in area of defects. All new bone tissue formed was surrounded by connective tissue, composed of moderate cellularity fusiform. After four weeks, a substantial area of compact bone in the surgical bed was seen surrounding areas of scarce bone marrow area in the defects. Collagenous stromal tissue completed the histological frame in this period. After six weeks, predominantly mature and Haversian compact bone tissue was observed surrounding occasional area of medullary tissue.

\section{Autogenous particulate bone graft + platelet concentrate}

Two weeks after surgery, the inserted bone fragments were observed surrounded by a rich collagen matrix composed by cellularity fusiform. Areas compatible with areas of new bone formation exhibiting basophilic reversal lines suggesting osteoconductor activity were scarce. On the fourth and the sixth week, it was observed an evident connective tissue consistent with fibrosis surrounding the bone tissue that increased slowly, as soon as the period of time progressed.

\section{Autogenous particulate bone graft + platelet-pour plasma}

On the second week, it was observed that autograft fragments surrounded by loose connective tissue that was composed of thin and delicate collagen fibers poorly cellularized with fusiform cellular content. This pattern was also observed in the fourth week after surgery. However, the amount of bone matrix was larger when compared to the anterior period. In the sixth week, it was observed a well-formed cancellous bone represented by Haversian bone matrix, as well as an intense well-formed medullar area that was composed of the exuberant presence of lymphoreticular cells and discreet fatty cells among the neoformed bone tissue.

\section{Platelet-pour plasma}

Microscopic analysis after two weeks revealed the presence of loose connective tissue with very few fusiform cells or new blood vessels. At four weeks, the histological pattern revealed a fibrotic tissue with scarce new bone formation derived from remaining host bone. At six weeks, the histological characteristics were similar. However, the amount of bone matrix deposition was larger when compared to four weeks.

\section{Control}

Histological analysis after two weeks revealed intense fibrous connective tissue compatible with reparative fibrosis, with very few fusiform cells or new blood vessels and reduced fatty cells. After four and six weeks, the histological patterns were similar and demonstrated an immature bonetissue in the adjacent host bone area and remaining fibrous tissue. 


\section{Immunohistochemical analysis}

The quantitative data for the histomorphometric results for bone matrix presence in each group are given in
Tables 2 and 3, for TGF- $\beta 1$ and OC, respectively. A concise description of immunohistochemical data found for each group is provided ahead.

Table 2 - Percentage of immunohistochemical presence of TGF- $\beta 1$ analysis among the groups*,**.

\begin{tabular}{|c|c|c|c|c|c|c|c|}
\hline Time period & & & PPP & ABG+PPP & $A B G+P C$ & ABG & Control \\
\hline \multirow{6}{*}{2 Weeks } & & & $12.65 \pm 1.73$ & $38.44 \pm 2.61$ & $76.05 \pm 3.11$ & $51.14 \pm 2.38$ & $17.22 \pm 1.67$ \\
\hline & PPP & $12.65 \pm 1.73$ & --- & $<0.001$ & $<0.001$ & $<0.001$ & 0.046 \\
\hline & $A B G+P P P$ & $38.44 \pm 2.61$ & & ---- & $=0.006$ & $=0.018$ & $<0.001$ \\
\hline & $A B G+P C$ & $76.15 \pm 3.11$ & & & --- & $=0.048$ & $<0.001$ \\
\hline & ABG & $51.14 \pm 2.38$ & & & & --- & $<0.001$ \\
\hline & Control & $17.22 \pm 1.67$ & & & & & ---- \\
\hline \multirow{6}{*}{4 Weeks } & & & $3.84 \pm 1.02$ & $3.08 \pm 1.69$ & $76.08 \pm 2.26$ & $48.11 \pm 1.74$ & $45.27 \pm 2.22$ \\
\hline & PPP & $3.84 \pm 1.02$ & ---- & $=0.746$ & $<0.001$ & $<0.001$ & $<0.001$ \\
\hline & $A B G+P P P$ & $3.08 \pm 1.69$ & & --- & $<0.001$ & $<0.001$ & $<0.001$ \\
\hline & $A B G+P C$ & $76.08 \pm 2.26$ & & & --- & $=0.015$ & $=0.028$ \\
\hline & $A B G$ & $48.11 \pm 1.74$ & & & & --- & $=0.704$ \\
\hline & Control & $45.27 \pm 2.22$ & & & & & ---- \\
\hline \multirow{6}{*}{6 Weeks } & & & $7.42 \pm 0.38$ & $4.83 \pm 1.66$ & $69.82 \pm 1.37$ & $37.77 \pm 2.17$ & $48.21 \pm 0.99$ \\
\hline & PPP & $7.42 \pm 0.38$ & --- & $=0.062$ & $<0.001$ & $<0.001$ & $<0.001$ \\
\hline & $A B G+P P P$ & $4.83 \pm 1.66$ & & ---- & $<0.001$ & $<0.001$ & $<0.001$ \\
\hline & $A B G+P C$ & $69.82 \pm 1.37$ & & & --- & $=0.024$ & $=0.003$ \\
\hline & $A B G$ & $37.77 \pm 2.17$ & & & & --- & $=0.066$ \\
\hline & Control & $48.21 \pm 0.99$ & & & & & --- \\
\hline
\end{tabular}

*Non-parametric Kruskal-Wallis test was employed; ${ }^{* *} \mathrm{p}<0.05$ indicates statistical significance; PPP: platelet-pour plasma; ABG: autogenous particulate bone graft; PC: platelet concentrate

Table 3 - Percentage of immunohistochemical presence of osteocalcin analysis among the groups*,**.

\begin{tabular}{|c|c|c|c|c|c|c|c|}
\hline Time period & & & PPP & ABG + PPP & $A B G+P C$ & ABG & Control \\
\hline \multirow{6}{*}{2 Weeks } & & & $8.32 \pm 0.42$ & $26.19 \pm 2.89$ & $34.07 \pm 2.51$ & $76.89 \pm 3.05$ & $44.62 \pm 1.18$ \\
\hline & PPP & $8.32 \pm 0.42$ & ---- & $<0.001$ & $<0.001$ & $<0.001$ & 0.046 \\
\hline & $A B G+P P P$ & $26.19 \pm 2.89$ & & ---- & $=0.624$ & $<0.001$ & $=0.002$ \\
\hline & $A B G+P C$ & $34.07 \pm 2.51$ & & & ---- & $<0.018$ & $=0.026$ \\
\hline & $A B G$ & $76.89 \pm 3.05$ & & & & ---- & $=0.002$ \\
\hline & Control & $44.62 \pm 1.18$ & & & & & ---- \\
\hline \multirow{6}{*}{4 Weeks } & & & $71.16 \pm 2.33$ & $17.11 \pm 1.49$ & $31.84 \pm 2.83$ & $71.16 \pm 2.33$ & $43.11 \pm 1.94$ \\
\hline & PPP & $4.38 \pm 0.87$ & ---- & $=0.046$ & $<0.001$ & $<0.001$ & $<0.001$ \\
\hline & $A B G+P P P$ & $17.11 \pm 1.49$ & & ---- & $<0.018$ & $<0.001$ & $<0.001$ \\
\hline & $A B G+P C$ & $31.84 \pm 2.83$ & & & ---- & $=0.022$ & $=0.028$ \\
\hline & ABG & $71.16 \pm 2.33$ & & & & ---- & $=0.044$ \\
\hline & Control & $43.11 \pm 1.94$ & & & & & ---- \\
\hline \multirow{6}{*}{6 Weeks } & & & $3.82 \pm 0.19$ & $14.28 \pm 1.42$ & $27.28 \pm 1.66$ & $69.08 \pm 2.73$ & $42.21 \pm 0.99$ \\
\hline & PPP & $3.82 \pm 0.19$ & ---- & $=0.006$ & $<0.001$ & $<0.001$ & $<0.001$ \\
\hline & $A B G+P P P$ & $14.28 \pm 1.42$ & & ---- & $=0.018$ & $<0.001$ & $<0.001$ \\
\hline & $A B G+P C$ & $27.28 \pm 1.66$ & & & ---- & $=0.002$ & $=0.003$ \\
\hline & ABG & $69.08 \pm 2.73$ & & & & ---- & $=0.044$ \\
\hline & Control & $42.21 \pm 0.99$ & & & & & ---- \\
\hline
\end{tabular}

Non-parametric Kruskal-Wallis test was employed; ${ }^{*} \mathrm{p}<0.05$ indicates statistical significance; PPP: platelet-pour plasma; ABG: autogenous particulate bone graft; PC: platelet concentrate 


\section{$\underline{\text { TGF- } \beta 1}$}

On the second week, all groups analyzed demonstrated positivity to TGF- $\beta 1$, as may be seen in Fig. 3. In the groups filled with PC, the immunopositivity was intense, and the percentage of positivity of TGF- $\beta 1$ was considerably significant higher than in $A B G$ and control groups. In contrast, the groups that received
PPP in the areas positive for TGF- $\beta 1$ were scarce, and its value was lower when compared to $A B G$ or control. On the fourth and sixth post-operative weeks, the pattern of TGF- $\beta 1$ was similar to groups $A B G$ and $A B G+P C$. However, for specimens that received PPP, the immunopositivity for TGF- $\beta 1$ decreased, while in the group control the positivity for TGF- $\beta 1$ increased as soon as that fibrotic area was formed.

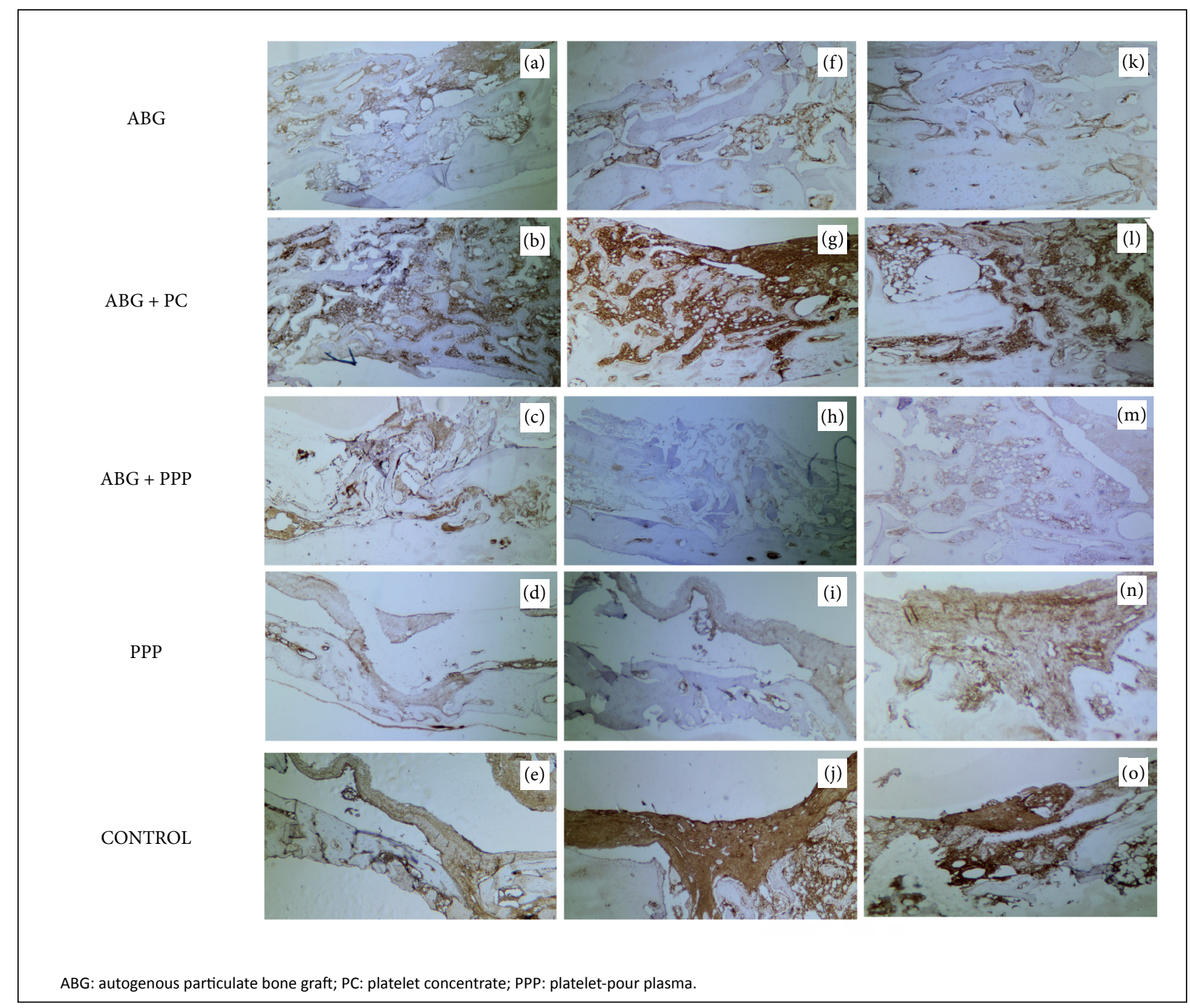

Figure 3 - Micrographs (a-e) demonstrate the pattern of distribution of immunoexpression of TGF- $\beta 1$ (brownish color) in the $A B G, A B G+P C, A B G+P P P$, PPP and control groups, respectively, two weeks after surgery. Verify the intense presence of TGF- $\beta 1$ in $A B G+P C$ group, while for the specimens in which PPP was inserted the immunopositivity for TGF- $\beta 1$ was scarce. Micrographs (f-j) demonstrate the same groups four weeks after surgery. The patterns of TGF- $\beta 1$ were suppressed in PPP groups, but the TGF- $\beta 1$ remains intense in specimens that received PC. These patterns were also similar to the sixth week (k-o). However, it was verified that the cytokine increased in extravascular area in specimens that received PPP. Micrographs (f-j) demonstrate the same groups on the sixth week after surgery. Verify the similar pattern of distribution of osteocalcin when compared to earlier stage of bone repair (second week) (original magnification $\times 100$ ). 


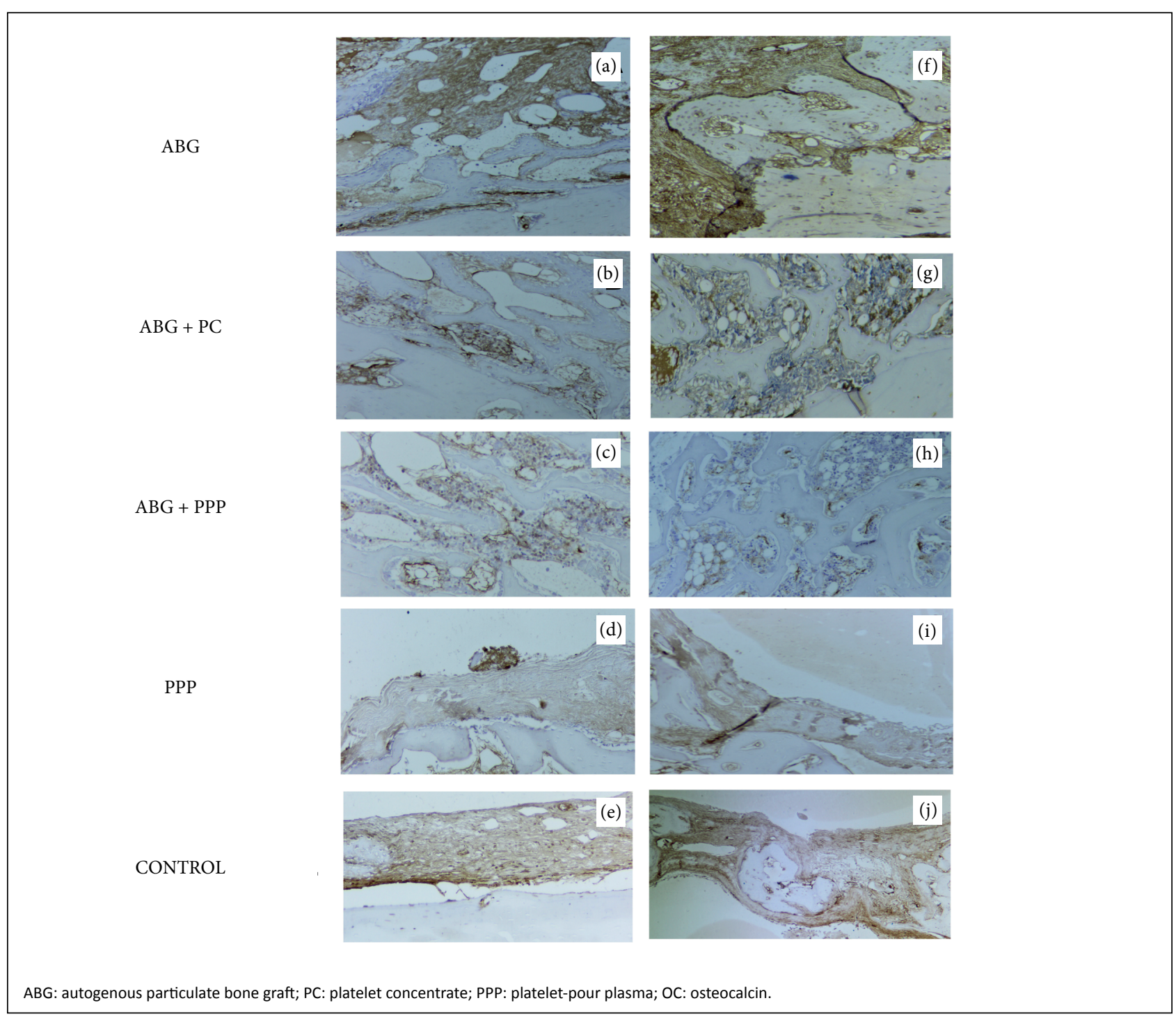

Figure 4 - Micrographs A, B, C, D and E demonstrate the pattern of distribution of immunoexpression of OC (brownish color) in the $A B G, A B G+P C, A B G+P P P, P P P$ and control groups, respectively, two weeks after surgery. Verify the intense presence of $O C$ on $A B G+P C$ group while in the specimens in which PC or PPP was inserted the immunopositivity for OC was fewer (brownish color). However, it was evident that specimens that were treated with $\mathrm{PC}$ revealed higher OC when compared to specimens that received PPP, associated or not to ABG (original magnification $\times 250$ ).

\section{Discussion}

Bone repair is a complex process that involves cell adhesion, proliferation, migration, differentiation, and synthesis and secretion of the peculiar extracellular matrix rich in collagen I, which possesses mineralization potential ${ }^{14}$.

It is necessary to emphasize that the approach of bone defects for study of bone healing may be heterogeneous ${ }^{15}$. However, the trauma in order to obtain surgical bed or on craniotomy approach may provide injuries, such as traumatic brain injury, as well as disruption of the blood-brain barrier integrity and the neurovascular unit, culminating in vascular leakage, edema, hemorrhage, hypoxia and neuronal death ${ }^{16}$. According to this premise, Özevren et al. ${ }^{16,17}$ demonstrated traumatic brain injury when cortical is injured or removed. The authors described a variety of pathological factors, such as oxidative stress, the inflammatory response, and apoptosis, as well as enlarged 
blood vessels, bleeding and swelling after traumatic injury in the brain and choroid plexus. On the other hand, Laçin et $a l .^{18}$ add that the presence of cortical or even its grafts provide a durable and rigid structure, condition that may give convenient model for evaluating bone regenerative effects of biomaterials. Herein we used the non-critical model created in rabbit calvaria, maintaining the cortical bone to assess the osteogenic effects of PC and PPP.

The use of $\mathrm{PC}$ in bone repair is based on the hypothesis that a significant number of platelets secrete an intense amount of active growth factors in response to granulation tissue at the injured site, especially collagen ${ }^{7}$. These growth factors seem to be responsible not only for proliferation, but also due to induction of differentiation of mesenchymal cells into osteoblasts ${ }^{6}$.

Although many studies have demonstrated a positive effect of PC on osteoneogenesis, others studies revealed deleterious results ${ }^{19}$. The lack of unanimous results about the effect of PC on bone regeneration is attributed to variations in the $P C$ preparations that could alter the platelet quality and/or quantity, which would result in differences in the regenerative potential of $\mathrm{PC}^{14-22}$. The PC production method used in this study has proven to be able to concentrate large amounts of platelets (upward of $6 \times$ concentration), differing from many authors who proposed the hypothesis that intermediate concentrations of platelets could optimize the repair, with maximum stimulation effects generated with approximate concentrations of $2.5 \times$, unlike what would occur with higher concentrations $s^{9,23}$.

Thus, distinct PC results could be correlated with this increase in platelets, whose action could stimulate a fibrous condition rather than osteogenesis, mimicking a pathological fibrosis effect simultaneously to the scarce bone matrix deposition, as found in the present study. This hypothesis is supported by Giovanini et al. ${ }^{24}$, who demonstrated a strong correlation between the presence of TGF- $\beta 1$ secreted by high-platelet concentration and a histological frame that mimicked a myelofibrosis. It should be highlighted that the intense production and positivity for TGF- $\beta 1$ produced by platelets also decrease the expression of important proteins that acts on canonical and noncanonical pathways of osteogenesis, such as BMP2 ${ }^{21}, \mathrm{Wnt}^{1}$ and osteoprotegerin levels ${ }^{23}$. Together, these hypotheses corroborate to results demonstrated herein and may explain the fewer amount of bone matrix development in areas in which $A B P+P C$ was used, associated to exuberant positivity for TGF- $\beta 1$, while the presence of $O C$ was scarce.

Differently from the idea stipulated for PC, previous studies have not identified several growth factors that possess proliferative capacity in $\mathrm{PPP}^{25}$. However, Cáceres et $a l .{ }^{26}$ found that, even in minor TGF- $\beta 1$ concentrations (4.4 times lower when compared to PC), osteoblastic cells responded similarly to PPP and PC, showing that favorable responses could be achieved using low concentrations of TGF- $\beta 1$. Yet, Yilmaz et $a l .{ }^{12}$ added that PPP may stimulate osteoblastic proliferation, increasing DNA synthesis and performing a mitogenic effect of osteoblasts, a condition that improves the osteoconductive effect.

Our results demonstrated that, in fact, the specimens that received PPP (associated or not to ABG) showed significant lower expression for TGF- $\beta 1$ when compared to other specimens. However, we also revealed that the osteogenesis was fewer when compared only to ABG, control or specimens that received PC. The result demonstrated herein differs of what was described by Cáceres et al. ${ }^{26}$ and Yilmaz et al. ${ }^{12}$. Herein we verified that the fewer bone formation coincided with concomitant scarce expression of both TGF- $\beta 1$ and OC in surgical area in which PPP was applied.

Yet, the results presented here revealed that, in the earliest stages of bone repair, PPP promoted larger quantities of thin and delicate extracellular matrix tissue added to autograft, while the majority of cells present in the regenerative sites were composed of fusiform cells. This result suggests that PPP induces cellular attachment, but the lack of growth factors suppresses the osteogenic differentiation in regenerative sites and favors a long period of usual medullary histophenotype, since it produces a stroma compatible with loose connective.

It is noteworthy that this cross-sectional study has some limitations. The analysis occurred only between two and six weeks in the postoperative period and no conclusions for immediate or latter effects of PC or PPP could be clarified. In addition, we used five defects produced in rabbit calvaria using distinct treatments. Under this context, we cannot evaluate the likely cross effect among the treatments neither cytokine action at a distance from the source that produced it.

Furthermore, there are many variables that generate doubts and need to be clarified for a safe use of autologous blood concentrates. For example, CP or PRPs have numerous growth factors, and the real interaction between them is unknown. There is also uncertainty as to whether these growth factors are competitive among them, or even if there is competition for a specific receptor to produce bone excitation or inhibition. Thus, as a future trend, further research is needed using a pool of growth factors which mimic the growth factors secreted by platelets, so they can be analyzed in different cell cultures to better understand 
how these factors interact (stimulating or inhibiting each other), and which factors act on cellular stimulation, expression of receptors or even as a transcription factor for osteogenic proteins.

\section{Conclusion}

It may be concluded that neither PC nor PPP increased the bone formation when their applications were in association with ABG grafts. Similarly, isolated use of PPP was not beneficial in optimizing the bone repair.

\section{Author's contribution}

Substantive scientific and intellectual contributions to the study: Oliveira Filho MA, Tabushi FI, Souza M and Almeida LE; Conception and design: Oliveira Filho MA, Figueiredo FP, Lourenço ES and Souza M. Data acquisition, analysis and interpretation: Giovanini AF and Ribas Filho JM; Histopathological examinations: Giovanini AF; Statistics analysis: Oliveira Filho MA and Alemira LE; Manuscript preparation: Giovanini AF; Manuscript writing: Giovanini $A F$, Figueiredo FP and Lourenço ES; Critical revision: Malafaia O; Final approval: Malafaia $\mathrm{O}$.

\section{Data availability statement}

Data will be available upon request.

\section{Funding}

Not applicable.

\section{Acknowledgments}

Not applicable.

\section{References}

1. Giovanini AF, Deliberador TM, Tannuri Nemeth JE, Crivellaro VR, Portela GS, Oliveira Filho MA, de Araujo MR, Zielak JC, Gonzaga CC. Leukocyte-platelet-rich plasma (L-PRP) impairs the osteoconductive capacity of the autograft associated to changes in the immunolocalization of TGF- $\beta 1$ and its co-expression with Wnt10b and CD34 cells. J Craniomaxillofac Surg. 2013;41(7):e180-86. http:// doi.org/10.1016/j.jcms.2013.01.003

2. Baldwin P, Li DJ, Auston DA, Mir HS, Yoon RS, Koval KJ. Autograft, allograft, and bone graft substitutes: clinical evidence and indications for use in the setting of orthopaedic trauma surgery. J Orthop Trauma. 2019;33:203-13. http://doi.org/10.1097/ ВОт.0000000000001420
3. Marx RE, Carlson ER, Eichstaedt RM, Schimmele SR, Strauss JE, Georgeff KR. Platelet-rich plasma: growth factor enhancement for bone grafts. Oral Surg Oral Med Oral Pathol Oral Radiol Endod. 1998;85:638-46. http:// doi.org/10.1016/s1079-2104(98)90029-4

4. Aghaloo TL, Moy PK, Freymiller EG. Investigation of platelet-rich plasma in rabbit cranial defects: a pilot study. J Oral Maxillofac Surg. 2002;60:1176-81. http://doi. org/10.1053/joms.2002.34994

5. Roh YH, Kim W, Park K U, Oh JH. Cytokine-release kinetics of platelet-rich plasma according to various activation protocols. Bone Joint Res. 2016;5:37-45. http://doi. org/10.1302/2046-3758.52.2000540

6. Messora MR, Nagata MJ, Dornelles RC, Bomfim SR, Furlaneto FA, de Melo LG, Deliberador TM, Bosco AF, Garcia VG, Fucini SE. Bone healing in critical-size defects treated with platelet-rich plasma activated by two different methods. A histologic and histometric study in rat calvaria. J Periodontal Res. 2008;43(6):723-9. http:// doi.org/10.1111/j.1600-0765.2008.01084.x

7. Giovanini AF, Deliberador TM, Gonzaga CC, de Oliveira Filho MA, Göhringer I, Kuczera J, Zielak JC, de Andrade Urban C. Platelet-rich plasma diminishes calvarial bone repair associated with alterations in collagen matrix composition and elevated CD34+ cell prevalence. Bone. 2010;46(6):1597-603. http://doi.org/10.1016/j. bone.2010.02.026

8. Petrera $M$, De Croos JNA, Iu J, Hurtig $M$, Kandel RA, Theodoropoulos JS. Supplementation with plateletrich plasma improves the in vitro formation of tissueengineered cartilage with enhanced mechanical properties. Arthroscopy. 2013;29:1685-92. http://doi. org/10.1016/j.arthro.2013.07.259

9. Oliveira Filho MA, Nassif PA, Malafaia O, Ribas Filho JM, Ribas CA, Camacho AC, Stieven Filho E, Giovanini AF. Effects of a highly concentrated platelet-rich plasma on the bone repair using non-critical defects in the calvaria of rabbits. Acta Cir Bras. 2010;25(1):28-33.https://doi. org/10.1590/s0102-86502010000100008

10. Arnoczky SP, Delos D, Rodeo SA. What is plateletrich plasma? Operative techniques in sports Medicine. 2011;19:142-8. https://doi.org/10.1053/j. otsm.2010.12.001

11. Cattaneo M, Lecchi A, Zighetti ML, Lussana F. Platelet aggregation studies: autologous platelet-poor plasma inhibits platelet aggregation when added to platelet-rich plasma to normalize platelet count. Haematologica. 2007;92:694-7. http://doi.org/10.3324/haematol.10999

12. Yilmaz S, Kabadayi C, Ipci SD, Cakar G, Kuru B. Treatment of intrabony periodontal defects with platelet-rich plasma versus platelet-poor plasma combined with a bovine-derived xenograft: a controlled clinical trial. J Periodontol. 2011;82:837-44. http://doi.org/10.1902/ jop.2010.100503 
13. Di Cataldo S, Ficarra E, Acquaviva A, Macii E. Automated segmentation of tissue images for computerized IHC analysis. Comput Methods Programs Biomed. 2010;100:115. http://doi.org/10.1016/j.cmpb.2010.02.002

14. Marsell R, Einhorn TA. The biology of fracture healing. Injury. 2011;42:551-5 http://doi.org/10.1016/j. injury.2011.03.031

15. Kadiroğlu ET, Akbalık ME, Karaöz E, Kanay BE, Dağ $A$, Ketani MA, Eroğlu EG, Uysal E, Tuncer MC. Calvarial bone defects in ovariectomised rats treated with mesenchymal stem cells and demineralised freeze-dried bone allografts. Folia Morphol (Warsz). 2020;79:720-35. http://doi. org/10.5603/FM.a2020.0001

16. Özevren H, Deveci E, Tuncer MC. The effect of rosmarinic acid on deformities occurring in brain tissue by craniectomy method. Histopathological evaluation of IBA-1 and GFAP expressions. Acta Cir Bras. 2020;35:e202000406. https:// doi: 10.1590/s0102-865020200040000006

17. Özevren H, Deveci E, Tuncer MC. Histopathological changes in the choroid plexus after traumatic brain injury in the rats: a histologic and immunohistochemical study. Folia Morphol (Warsz). 2018;77:642-8. https://doi: 10.5603/FM.a2018.0029

18. Laçin N, İzol BS, Özkorkmaz EG, Deveci B, Tuncer MC. The effect of graft application and allopurinol treatment on calvarial bone defect in rats. Acta Cir Bras. 2019;34:e201900306. http://doi.org/10.1590/s0102865020190030000006

19. Intini $G$. The use of platelet-rich plasma in bone reconstruction therapy. Biomaterials. 2009;30:4956-66. http://doi.org/10.1016/j.biomaterials.2009.05.055

20. Nikolidakis D, Jansen JA. The biology of platelet-rich plasma and its application in oral surgery: literature review. Tissue Eng Part B Rev. 2008;14:249-58.http://doi. org/10.1089/ten.teb.2008.0062

21. Giovanini AF, Grossi JR, Gonzaga CC, Zielak JC, Göhringer I, Vieira J de S, Kuczera J, de Oliveira Filho MA, Deliberador TM. Leukocyte-platelet-rich plasma (L-PRP) induces an abnormal histophenotype in craniofacial bone repair associated with changes in the immunopositivity of the hematopoietic clusters of differentiation, osteoproteins, and TGF- $\beta 1$. Clin Implant Dent Relat Res. 2014;16(2):25972. http://doi.org/10.1111/j.1708-8208.2012.00478.x

22. Murray IR, LaPrade RF. Platelet rich plasma: renewed scientific understanding must guide appropriate use. Bone Joint Res. 2016;5:92-82 http://doi.org/10.11302/20143758.53BJR-2016-0005

23. Graziani F, Ivanovski S, Cei S, Ducci F, Tonetti M, Gabriele $M$. The in vitro effect of different PRP concentrations on osteoblasts and fibroblasts. Clin Oral Implants Res. 2006;17(2):212-9. http://doi.org/10.1111/j.16000501.2005.01203.x

24. Giovanini AF, Gonzaga CC, Zielak JC, Deliberador TM, Kuczera J, Göringher I, de Oliveira Filho MA, BarattoFilho F, Urban CA. Platelet-rich plasma (PRP) impairs the craniofacial bone repair associated with its elevated TGF- $\beta$ levels and modulates the co-expression between collagen III and $\alpha$-smooth muscle actin. J Orthop Res. 2011;29(3):457-63. http://doi.org/10.1002/jor.21263

25. Schnabel LV, Mohammed HO, Miller BJ, McDermott WG, Jacobson MS, Santangelo KS, Fortier LA. Platelet rich plasma (PRP) enhances anabolic gene expression patterns in flexor digitorum superficialis tendons. J Orthop Res. 2007;25(2):230-40. http://doi.org/10.1002/jor.20278

26. Cáceres M, Martínez C, Martínez J, Smith PC. Effects of platelet-rich and -poor plasma on the reparative response of gingival fibroblasts. Clin Oral Implants Res. 2012;23:1104-11. http://doi.org/10.1111/j.16000501.2011.02274.x

27. Rivera-Chacon DM, Alvarado-Velez $M$, Acevedo-Morantes CY, Singh SP, Gultepe E, Nagesha D, Sridhar S, RamirezVick JE. Fibronectin and vitronectin promote human fetal osteoblast cell attachment and proliferation on nanoporous titanium surfaces. J Biomed Nanotechnol. 2013;9(6):1092-7. http://doi.org/10.1166/jbn.2013.1601 